\title{
Perceptual and cognitive processes in time-to-contact estimation: Analysis of prediction-motion and relative judgment tasks
}

\author{
J. R. TRESILIAN \\ MRC Applied Psychology Unit, Cambridge, England
}

\begin{abstract}
Three classes of task appear to involve time-to-contact (TTC) information: coincidence anticipation (CA) tasks, relative judgment (RJ) tasks, and interceptive actions (IAs). An important type of CA task used to study the perception of TTC is the prediction-motion (PM) task. The question of whether it is possible to study the perceptual processes involved in the timing of IAs using PM and RJ tasks is considered. A revised version of the tau hypothesis is proposed as an account of the perceptual information processing involved in the control of fast IAs. This draws on the distinction between "motor" and "cognitive" visual systems. It is argued that task variables affect whether "cognitive" information processing is involved in performance and can determine whether TTC information is used at all. Evidence is reviewed that suggests that PM and RJ tasks involve cognitive processing. It is argued that target viewing time, TTC at response initiation, amount of practice, and whether there is a period between target disappearance and response are task variables that determine whether cognitive processing will influence responding.
\end{abstract}

The ability to estimate the time remaining before something reaches a person or particular place - its time to arrival or time to contact (TTC) - appears to be important in a variety of real-world tasks, such as catching and hitting balls (Bahill \& Karnavas, 1993; Bootsma \& van Wieringen, 1990; Lee, 1980; McLeod, McLaughlin, \& Nimmo-Smith, 1985; Regan, 1992), driving (Cavallo \& Laurent, 1988; Lee, 1976), jumping (Lee, 1980; Lee, Lishman, \& Thompson, 1982), and placing the feet while running (Warren, Young, \& Lee, 1986). Tasks like these will be referred to as interceptive actions (IAs), although some involve an avoidance movement (e.g., jumping). Studies of timing performance in IAs are consistent with the idea that the performer of the task derives information about TTC from the sensory input. Laboratory studies of the ability to derive TTC information often employ tasks that can be classed into two broad groups: coinci-

The work was supported by the Medical Research Council of Great Britain. I would like to thank Alan Wing for his comments on a draft version of this paper. Thanks also to Myron Braunstein, D. J. Law, and two anonymous referees for their extensive and very useful criticism and suggestions that helped considerably in improving the manuscript. Correspondence should be addressed to J. R. Tresilian, Medical Research Council, Applied Psychology Unit, 15 Chaucer Rd., Cambridge CB2 2EF, England (e-mail: james.tresilian@mrc-apu.cam.ac.uk). dence anticipation (CA) and relative judgment (RJ) tasks.

In the CA task, subjects are required to make a simple response (e.g., press a button) at the same moment as a moving target arrives at a specified position, which will be called here the contact point. An important type of CA task involves the moving target disappearing from view before it reaches the contact point; the subject is then required to make a response that coincides temporally with the target's assumed arrival at the contact point. Such CA tasks are often referred to as predictionmotion (PM) tasks.

In the RJ task, subjects indicate which of two approaching targets will arrive first after they disappear. It is not, in principle, necessary for the observer to wait until the target disappears before making a response in this type of task. In most experiments, it appears that the response is made after target disappearance, but the observer can respond immediately rather than waiting until the target is judged to have reached them (were it to have continued). A recent study reported by Regan and Hamstra (1993) employed an interesting variant of the RJ task based on a psychophysical method previously used by McKee (1981). Observers were required to indicate on each trial whether a single target would arrive at a contact point earlier or later than the mean time of arrival for the complete set of 
stimuli, which served as a form of internalized reference time.

It has been usual to use PM and RJ tasks to study the perceptual skills presumed to be involved in the timing of IAs. From time to time, CA tasks (other than PM tasks) are employed, though their use is less frequent (e.g., Bootsma, 1989; McLeod et al., 1985; Tresilian, 1994a). PM and RJ tasks will be the major concern in what follows. Performance in these tasks may be considered a legitimate study in its own right. Nevertheless, it is often hoped that these tasks can be used to study, under controlled conditions, the perceptual processes involved in the timing of skilled IAs.

A popular hypothesis concerning what the perceptual processes are doing in fast IAs is the tau hypothesis associated with D. N. Lee (e.g., 1976). Fast IAs, such as catching a ball or returning a serve in tennis, are characterized by their brief execution time (they are fast), and there is typically only a brief period available for viewing the moving target. There are other much slower IAs, but little research has been conducted on their timing; most of these, like crossing the road or braking, involve avoidance of a target. Little more will be said about such slow IAs; they are mentioned here for the sake of completeness.

The tau hypothesis concerns the type of information that is extracted perceptually and used to time fast IAs; it is described in detail later. PM and RJ tasks are frequently used to test this hypothesis (e.g., Cavallo \& Laurent, 1988; DeLucia, 1991; Kaiser \& Mowafy, 1993; McLeod \& Ross, 1983), and favorable results derived using these paradigms are often cited in its support (e.g., Lee, Reddish, \& Rand, 1991; Lee \& Young, 1985). Nevertheless, it is not clear if and when results from these tasks can be used to draw conclusions about the perceptual information used to time IAs. The following question arises: Is it possible to study the perceptual processes involved in the timing of IAs using PM and RJ tasks?

PM tasks, RJ tasks, and IAs differ in a number of ways that may influence the information used and the manner in which that information is processed. The tau hypothesis is explicit about the type of information and the type of information processing involved in fast IAs (e.g., Lee, 1980; Turvey \& Carello, 1986). Although the tau hypothesis is untenable in its original form (see Section 1.3 below), it can be developed to provide a good account of timing performance in IAs (Tresilian, 1994c). An outline of this development is provided in the next section, together with a detailed account of the type of perception-response linkage that the hypothesis proposes. This "revised tau hypothesis" is proposed as a hypothesis for the type of information and information processing involved in fast IAs. We then go on to consider how the information and information processing involved in PM and RJ tasks might differ from that involved in IAs, and what critical task variables lead to differences.

\section{TIMING FAST INTERCEPTIVE ACTIONS: THE "TAU HYPOTHESIS"}

\subsection{The "Tau-Function" Notation}

The most convenient notation for discussing tau hypotheses is the tau-function notation recently introduced by Lee (1992; Lee et al., 1991). The basic notational device is extremely simple: if $X$ is a time varying quantity and $\dot{X}$ is its temporal derivative, the tau function of $X$, written $\tau(X)$, is defined to be $X / \dot{X}$ and has the dimension of time. If $-X$ is the distance of an approaching target from an observer or some other designated place, then the quantity $-\tau(X)$ is sometimes referred to as the tau margin (Lee \& Young, 1985). By definition, the tau margin is equal to the TTC of the target with the observer (or designated point), were the velocity to remain constant. The tau margin provides a first-order approximation to the actual TTC when the velocity is not constant. For this reason, in what follows I will not use the term "tau margin," which I think is confusing, but use first-order TTC instead (as shorthand for "first-order approximation to the actual TTC").

\subsection{The Old Version of the Tau Hypothesis}

I will begin by describing the "old" tau hypothesis, which, until recently, appears to have been widely accepted as the major hypothesis concerning how IAs are timed. It is, however, difficult to locate an explicit statement of this old tau hypothesis in the literature, but it is clear from numerous publications that most people consider the tau hypothesis to have this form (e.g., Bruce \& Green, 1985; Cavallo \& Laurent, 1988; DeLucia, 1991; Hofsten, 1983; Hofsten \& Lee, 1982; McLeod \& Ross, 1983; Nakayama, 1994; Savelsbergh \& van Emmerik, 1992; Turvey \& Carello, 1986).

The old tau hypothesis may be summed up as two propositions:

(A) Estimates of first-order TTC are used to time fast IAs and are derived directly from the tau functions of optic variables.

(B) In timing fast IAs, the perceptually measured tau variables are used to control temporal parameters of movements-perceptuomotor control involves a fast, direct route from perception to action that bypasses cognitive operations.

As an example of a perceptual tau variable that provides first-order TTC information, consider the solid angle, $\Omega$, subtended at an observer's eye by a ball a distance of $-Z$ from, and directly approaching, the eye. In this case, $-\tau(Z)=2 \tau(\Omega)$ : the first-order TTC of the ball with the eye is specified by the tau-function of visual solid angle. If it is supposed that the area of the ball's retinal image is directly proportional to $\Omega$ and is a quantity measurable by the visual system, then the firstorder TTC can be "computed."

The old tau hypothesis has three important corollaries: (1) the constant velocity approximation strategy- 
first-order TTC is used rather than the actual TTC when the velocity is changing, (2) the eye-contact approximation strategy-information about the TTC with the eye is used that only approximates the TTC of the moving target with the effector, and (3) TTC perception involves only optic variables. The basic information-processing structure of the old tau hypothesis is shown in Figure 1 (left panel).

\subsection{The Revised Version of the Hypothesis}

It has long been clear that the old tau hypothesis is unable to account for the timing skill demonstrated in interception tasks such as catching and hitting, the most significant problem being the eye-contact approximation (e.g., Bootsma \& Oudejans, 1993; Hofsten, 1983; Tresilian, 1990). In addition, it is clear from recent experimental work that sensory systems other than vision can play a role in TTC perception (Rosenblum, Wuestefeld, \& Saldana, 1993; Schiff \& Oldak, 1990; Tresilian, 1994a; see also, Heuer, 1993; Lee, 1992; Shaw, McGowan, \& Turvey, 1991; Tresilian, 1990). In response to these findings, I have developed what I will call the revised tau hypothesis, which preserves Proposition B of the older version but replaces Proposition A with an alternative that may be briefly stated as follows:

( $\left.\mathrm{A}^{\prime}\right)$ Perception of TTC is based on the first-order TTC about which there are typically a number of different sources of perceptual information available to an observer. These sources of information may be derived from the combined efforts of several sensory systems, and the final estimate of TTC used to control actions is usually the result of a combination of several different information sources.

The basic information-processing structure of this hypothesis is shown in Figure 1 (right panel). Theoretical work demonstrated that there are a number of sources of first-order TTC available to an observer, some monocular and others binocular (Tresilian, 1990, 1993; see also Bootsma \& Oudejans, 1993; Heuer, 1993). These sources are defined as mathematical relationships between several proximal stimulus variables.

Extraction of TTC information involves first extracting the relevant stimulus variables from the sensory input. This process is complicated by the fact that these variables may be available in the input to more than one sensory system, and hence the perceptual processor is potentially faced with the problem of selecting between or combining the measurements of the variables provided by the different system. The next step is to derive various TTC estimates from the measured stimulus variables.

The "influencing factors" shown in Figure 1 (right panel) are here assumed to be noncognitive in nature, following the conclusion of McLeod et al. (1985). The role of cognitive factors is limited to manipulating the input to the mechanism by shifts of gaze or "attention" and perhaps to switching the mechanism "on" and "off." McLeod et al. proposed the notion of an "information-

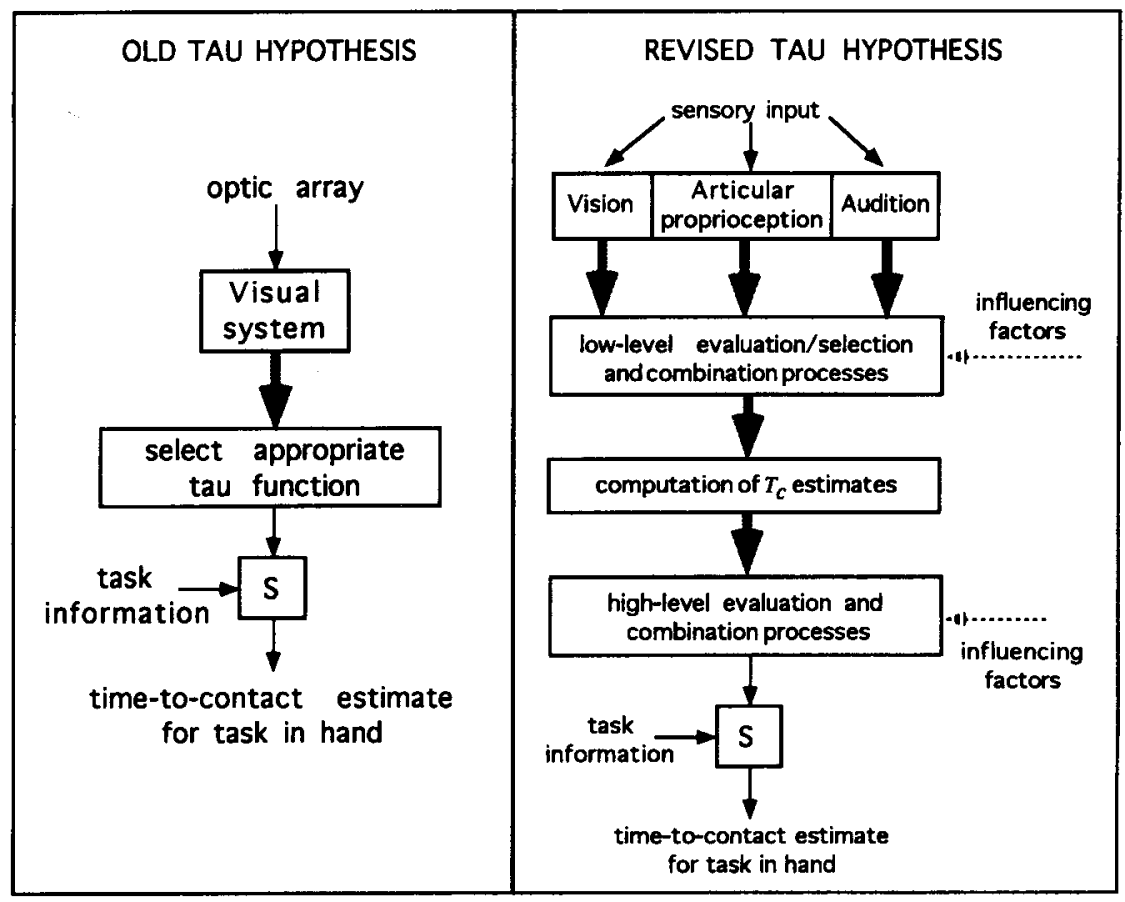

Figure 1. Left panel: the old tau hypothesis. Right panel: the new tau hypothesis as described in Tresilian (1994c, Figure 2). The box labeled $S$ indicates the process that scales the TTC information into units appropriate for the task being performed. 
ally encapsulated" TTC processor that is "uninfluenced by other cognitive activities" and "general cognitive resources" (McLeod et al., 1985, p. 392), which follows the definition of Fodor (1983). The idea translates into the present context as the assertion that the perceptual structure illustrated in Figure 1 (right panel) is informationally encapsulated in this sense. This is acceptable insofar as McLeod et al.'s "cognitive activities" are not perceptual since TTC processing is here hypothesized to be influenced by a number of concurrent perceptual processes. In what follows, when tau hypothesis is mentioned, it will refer to the revised tau hypothesis just described.

\subsection{A Caveat Concerning the Generality of the Tau Hypothesis}

Lacquaniti has interpreted some experiments on catching (Lacquaniti \& Maioli, 1989) as evidence against the use of a constant velocity approximation in interceptive timing and, by implication, against the tau hypothesis. These authors dropped balls of various masses from various heights $(0.2,0.4,0.8$, and $1.2 \mathrm{~m})$ into the subject's waiting hand. Electromyographic (EMG) responses were recorded in the biceps, triceps, and wrist extensors and flexors. Two EMG response components were identified: the early components were observed to occur at an approximately constant latency of $130 \mathrm{msec}$ after ball release; the late components were observed to begin at an approximately constant TTC of $100 \mathrm{msec}$ in all muscles except the wrist extensors, independently of ball drop height. Note that no late component was present in drops of $0.2 \mathrm{~m}$.

An EMG onset time that is independent of drop height is not consistent with the strategy of initiating muscle activation at a constant value of $-\tau(X)$ (where $X$ is the distance of the ball from the hand). This strategy predicts that EMG onset should be later, the lower the drop. Lacquaniti and Maioli's results can be considered to refute the hypothesis that muscles are activated at a constant value of $-\tau(X)$. However, the strategy of initiating movement or muscle activation at a constant value of $-\tau(X)$ represents a hypothesis that goes beyond the proposition that $-\tau(X)$ is used to time interceptions and that is refuted by data from a variety of sources (e.g., Bootsma \& van Wieringen, 1990; Tresilian, 1994b; Wallace, Stevenson, Weeks, \& Kelso, 1992). The fact that movements or muscle activations are not initiated at a constant value of $-\tau(X)$ does not contradict the tau hypothesis.

Nevertheless, Lacquaniti and Maioli's results are consistent with the hypothesis that muscle activations and movements are initiated at a constant TTC. What is not clear is whether their results are consistent with a strategy in which muscle activation is initiated at a value of $-\tau(X)$ that depends on other factors, such as object momentum. It is certainly possible that $-\tau(X)$ was not used to control the timing of muscle activations in Lacquaniti and Maioli's experiments and that something else-for example, an estimate of the actual TTC computed from the drop height of the ball (Tresilian, 1993) - was used instead. Indeed, the task used by Lacquaniti and Maioli is of exactly the kind in which one would not expect a person to use $\tau(X)$ information.

The task involved objects falling very short distances $(\leq 1.2 \mathrm{~m})$ under gravity. In such circumstances, use of $-\tau(X)$ information will be very unreliable. People typically experience many situations where objects fall vertically, or nearly so, a few tens of centimeters from one hand to the other, from the hand to the foot, and so forth. It would not be surprising, therefore, if people learned to exploit the simple fact that the time that the object will take to drop a short distance can be predicted from a measurement of that distance, which could be made very accurately if the distance was relatively small. It is certainly not necessary to suppose, as Lacquaniti and Maioli (1989) do, that an estimate of the actual TTC is computed from the image of a moving target using information about distance, velocity, and acceleration. This illustrates the possibility that there are IAs that are not timed using $-\tau(X)$ information.

\subsection{Direct Perception-Action Coupling}

The direct perception-action coupling proposed in the tau hypothesis establishes what is sometimes called a "perception-action" system (e.g., Hofsten, 1987; Turvey \& Carello, 1986) - an autonomous special-purpose control system instantiated for performance of a particular type of action. In Arbib's (1981) terms, the control system is the result of coupling a perceptual schema (the TTC extraction device) and a motor schema (the taskspecific motor control system). This, of course, has some similarity to notions concerning motor programs (e.g., Schmidt, 1982).

That there is a route from perception to action in motor control, which is different from the route that creates representations upon which cognitive processes can act, is suggested by the recent work of Goodale and colleagues (e.g., Goodale \& Milner, 1992), who have proposed an interpretation of the function of the two streams in the visual cortex (see, e.g., Ungerleider \& Mishkin, 1982) that differs somewhat from the focal/ ambient distinction of the original two visual systems hypothesis (Trevarthen, 1968).

The ventral pathway in the neocortex from V1 to the inferotemporal cortex is concerned with the perceptual processes underlying object recognition and identification; the dorsal pathway from V1 to the posterior parietal region mediates visually guided actions. Goodale and Jakobson (1992) express this by stating that the processing carried out in the ventral stream underlies the "formation of perceptual and cognitive representations ... Those carried out in the dorsal stream, which utilize the instantaneous and egocentric features of objects, mediate the control of goal directed actions" (p. 747).

Important neuropsychological evidence for this hypothesis was reported by Goodale, Milner, Jakobson, and Carey (1991), who discussed the case of a woman suffering from profound visual form agnosia. She was 
quite unable to verbally report the orientation and size of visible objects or to indicate them manually. This same patient was, however, able to reach for and grasp visible objects in a normal fashion - the grasp aperture was adjusted to the size of the object and the hand was oriented appropriately for the orientation of the object. This patient demonstrates a clear dissociation of the visual processes underlying conscious perceptual judgments and those involved in automatic visuomotor control. The idea that the perceptual processes underlying the control of movement and those involved in perceptual phenomenology become dissociated relatively early in the visual system reinforces the notion that perceptuomotor control involves a fast direct route to the motor system.

Further evidence for different visual streams for motor control and perceptual judgments comes from Goodale, Pelisson, and Prablanc's (1986) observation that sudden changes in target location during reaching can result in a modification of the limb trajectory such that it moves to the new target location without the subject's being aware that the target location has changed. This result is obtained when the location change occurs during the subject's initial saccade to the target location. Bridgeman, who has reported similar results (Bridgeman \& Lewis, 1976; Bridgeman, Lewis, Heit, \& Nagle, 1979), also proposes two visual streams, one involved in motor control and one in making cognitive judgments, and has concluded that "information can be routed independently to the cognitive or motor visual systems, so that a change in the information present in one of the systems need not significantly influence the information in the other" (Bridgeman, Kirch, \& Sperling, 1981, p. 341). It seems reasonable to identify the fast direct route hypothesized in the tau hypothesis with the motor visual system.

Perceptual timing of IAs is thus hypothesized to be achieved by a special-purpose control system involving the motor visual system. Such timing can be identified as an "automatic" process in the sense used by, for example, Bargh (1992), Logan and Cowan (1984), and Schneider and Shiffrin (1977). Specifically, Bargh identified various possible types of automatic process, that relevant to interceptive timing he calls "goal-directed automaticity." This refers to processes or activities that require special stimulus preconditions or need to be intended by the person in order to be executed; however, once started, they run off by themselves without being influenced by conscious processes.

It is characteristic to suppose that skill acquisition in general involves a transition from an initial cognitively controlled unskilled stage to an automatic skilled stage (e.g., Ackerman, 1988; Anderson, 1982; Fitts \& Posner, 1967; Schneider \& Shiffrin, 1977): the initial stage is highly attention demanding, whereas the latter stage is not. However, the automatic process of the specialpurpose control system involved in skilled IAs is assumed to involve selection of a fast direct route to action mediated by the "motor visual system" of Bridgeman et al. (1979) and Goodale and Milner (1992). Thus, skill acquisition in IAs does not involve the automation of cognitive operations on perceptual information as might be supposed if one applied, for example, Anderson's (1982) theory of automation. The idea is that the automatic process (the control system) bypasses all cognitive operations (automatic or not). Thus, it is important to note that the cognitive route can involve automatic processes (i.e., not involving conscious cognitive control), but these are part of a slower, less direct perceptuomotor linkage.

McLeod et al. proposed, following Schneider and Shiffrin (1977), that if fast IAs involve a fast route from perception to action, skill acquisition should involve decreasing response latencies and most importantly decreasing response variability in performance as cognitive processing stages are eliminated. However, there are likely to be a variety of additional reasons for decreasing variability that are not due to the elimination of cognitive processing stages. For example, the perceptuomotor coupling may become more specific with practice. Early on, a variety of different information sources, which may be only weakly correlated with the required quantity, may contribute to the response. Practice eliminates the less informative sources of information (whose variability relative to the required quantity may be high due to the weak correlation) and decreases variability as a result. Evidence that this can occur is discussed later in Section 4.

Another idea is that the nature of the perceptuomotor coupling changes with practice. For example, early on, the act may not be controlled in an on-going fashion; however, with practice, it comes to admit such control. It appears that highly skilled actions involving precise timing tend to be controlled in an on-going fashion since their temporal variability decreases during execution (e.g., Bootsma \& van Wieringen, 1990). There is other evidence that the nature of the perceptuomotor organization in interceptive timing tasks changes with practice in a manner that admits greater on-going control (Young \& Schmidt, 1990). Thus, the effects of practice are certainly not restricted to the formation of a direct perceptionaction coupling - the coupling itself can change and improve with practice, and this is likely to lead to decreases in performance variability.

A schematic representation of the hypothesis that has been described here is shown in Figure 2. "Early" or noncognitive perceptual processing that is data driven (though it may involve feedback loops and be subject to higher level "attentional" modulation) includes the TTC processing described above and shown schematically in Figure 1 (right panel). Information extracted at this level may be fed along a fast direct route to the motor control system and/or along a slow route involving cognitive perceptual operations. It may be possible to imagine many variants of this basic scheme. For example, Figure 2 shows the early processing as being the locus of the combination of different sources of TTC information described above. As yet, the best evidence for such com- 


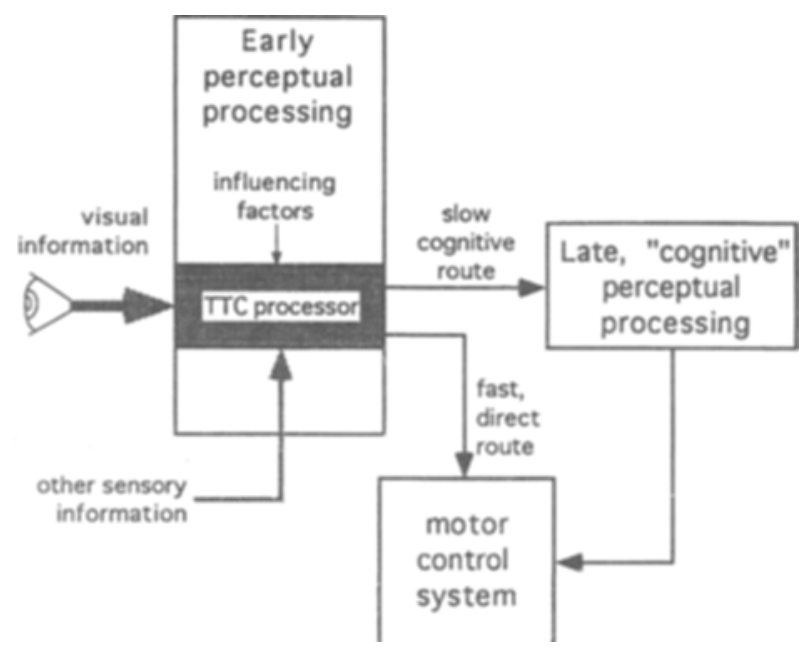

Figure 2. Schematic representation of the hypothesis described in the text, showing two possible means of linking perception and response.

bination comes from Heuer's (1993) experiment, which used a PM task and may, as a consequence, have involved the slow cognitive route (see below).

\section{PERCEPTUOMOTOR COUPLING IN DIFFERENT TYPES OF TASK INVOLVING TTC ESTIMATION}

What task differences could influence the type of perceptuomotor coupling operative in IAs, PM, and RJ tasks? Fast IAs are typically characterized by the following. (1) Brief execution times: The reach and grasp movement in one-handed catching lasts about $300 \mathrm{msec}$ (Alderson, Sully, \& Sully, 1974); a baseball strike or tennis stroke from start to contact may be even shorter than this (e.g., Bahill \& Karnavas, 1993). (2) Brief targetviewing times: It is apparent from the performance of different IAs that people can reliably achieve a temporal precision of within $10 \mathrm{msec}$ when the target is visible for only a few hundred milliseconds (e.g., Bootsma \& van Wieringen, 1990; McLeod et al., 1985; Regan, 1992; Tresilian, 1994a). A comparable precision can be achieved with viewing times of less than about $100 \mathrm{msec}$ (Sharp \& Whiting, 1975; Whiting, Gill, \& Stephenson, 1970). (3) Initiation of movement at small TTCs $(\approx$ execution time + visuomotor delay). (4) Initiation of movement when TTC information is available. (5) High level of practice.

In addition, there is the possibility of controlling movements in an on-going fashion using TTC information available during execution (e.g., Lee, Young, Reddish, Lough, \& Clayton, 1983) and the possibility that execution times are determined by the TTC at initiation, when the action is too brief to admit on-going control (Bootsma, 1989; Tresilian, 1994c).

In PM tasks, the target typically disappears when the time remaining until contact is quite large: the display typically terminates at least $1 \mathrm{sec}$ and sometimes as much as $10 \mathrm{sec}$ (Schiff \& Detwiler, 1979) before the moving target would have reached the contact point. Consequently, the initiation of the response (a buttonpress made such that it coincides in time with the target's arrival at the contact point) often occurs seconds after target disappearance and cannot be initiated or controlled using perceptually available TTC information. The observer must wait until the appropriate moment arrives and then press the button: the appropriate moment to initiate the response must be based on information obtained from the target some time before it disappeared. One could view the time for which an observer must wait before pressing the button (a time that is determined by information obtained before disappearance) as a sort of "covert" timed response.

The situation with RJ tasks is complicated by the fact that these tasks are not timing tasks in the same sense that IAs and PM tasks are. IAs appear to be both initiated and controlled using perceptually available TTC information. PM tasks also involve timing: observers are required to respond such that the response is temporally coincident with the target's predicted arrival at the contact point. Timing of this kind is conspicuously absent from RJ tasks: the observer need only indicate which of two (or more) targets will arrive at some contact point first; the response does not need to be timed so that it is temporally coincident with any external event nor does it need to be initiated or controlled using TTC information. In an RJ task, the observer only needs to decide which target will arrive first, and there may be a variety of cues (which do not inform about when a target will arrive) that could be reliably used to do this. Importantly, although RJ tasks may involve using TTC information to make the correct response, no actual timing is involved. The differences between the different types of task discussed here are summed up in Table 1.

On the basis of these considerations, it may be tentatively proposed that the perceptuomotor processes involved in PM and RJ tasks are not the same as those involved in the performance of fast IAs. The following working hypothesis is examined below: In general, $P M$ and RJ tasks involve the Bridgeman/Goodale cognitive visual system. However, the greater the similarity between a PM or an RJ task and an IA (in execution time, viewing time, level of practice, TTC at movement initiation, and when TTC information is available), the more likely it is that the contribution of the cognitive visual system will be minimal. PM and RJ tasks are considered in turn.

\section{COGNITIVE OPERATIONS IN PREDICTION-MOTION TASKS AND THE GENERALITY OF EXPERIMENTAL RESULTS}

In this section, we will consider the following areas of difference between PM tasks and fast IAs (see Table 1): (1) whether perceptual TTC information is available at 
Table 1

Differences Between Various Types of Task Involving Time-to-Contact (TTC) Estimation

\begin{tabular}{|c|c|c|c|c|}
\hline & \multicolumn{2}{|r|}{ IAs } & \multicolumn{2}{|c|}{ Tasks } \\
\hline & Fast & $\begin{array}{c}\text { Slower } \\
\text { (Road Crossing) }\end{array}$ & PM & $\mathrm{RJ}$ \\
\hline Timed response? & yes & yes & yes & no \\
\hline Brief execution time? & yes & no & yes & yes \\
\hline Target visible for long period? & rarely & usually & usually & usually \\
\hline $\begin{array}{l}\text { Initiation of timed response } \\
\text { at small TTC? }\end{array}$ & yes & no & yes & $\mathrm{n} / \mathrm{a}$ \\
\hline $\begin{array}{l}\text { TTC information available } \\
\text { at initiation? }\end{array}$ & yes & yes & no & yes \\
\hline $\begin{array}{l}\text { Possible for TTC to determine } \\
\text { response duration? }\end{array}$ & yes & yes & no & $\mathrm{n} / \mathrm{a}$ \\
\hline Ongoing control possible? & usually & usually & no & $\mathrm{n} / \mathrm{a}$ \\
\hline Highly practiced? & yes & yes & no & rarely \\
\hline
\end{tabular}

Note-IA = interceptive action, $\mathrm{PM}=$ predictive motion, $\mathrm{RJ}=$ relative judgment, and $\mathrm{n} / \mathrm{a}=$ not applicable because $\mathrm{RJ}$ tasks do not involve a timed response.

the moment of movement initiation, and (2) whether the moving target is visible for a relatively long period of time before response initiation or whether it is only briefly visible.

\subsection{Importance of Information Availability at Response Initiation}

That there are important differences between cases where the target disappears before the response is initiated as compared with when it is initiated after target disappearance is suggested by the differences between results obtained by Whiting and colleagues (e.g., Whiting \& Sharp, 1974) and those obtained in PM tasks. In experiments using PM tasks, TTC is typically underestimated at about $60 \%$ of the actual value (on average) when the major component of the target's velocity is directly toward the observer (Groeger \& Brown, 1986; McLeod \& Ross, 1983; Schiff \& Detwiler, 1979; Schiff $\&$ Oldak, 1990). Second, the variability in TTC estimates increases with increases in the value of the actual TTC. Third, the standard deviation of the estimates tends to be nearly $50 \%$ of the actual TTC. In the Schiff and Detwiler study, for example, the standard deviation of the estimates across subjects was about $4.4 \mathrm{sec}$ at a TTC of $10 \mathrm{sec}, 4 \mathrm{sec}$ at a TTC of $8 \mathrm{sec}, 2.8 \mathrm{sec}$ at a TTC of $6 \mathrm{sec}$, and $1.8 \mathrm{sec}$ at a TTC of $4 \mathrm{sec}$ (estimated from Schiff and Detwiler's, 1979, Figure 2). This pattern of results means that errors in TTC judgment in the PM tasks can be enormous - in the Schiff and Detwiler study, some subjects occasionally judged a TTC of $10 \mathrm{sec}$ to be about $1 \mathrm{sec}$.

Typically, a linear model is used to fit the data obtained in PM tasks, for both direct approaches and approaches between a moving target and a contact point lying parallel to the observers' frontal plane. Yakimoff and colleagues have shown that such a model, taking the form $T_{r}=\alpha(\mathrm{TTC})+c \quad$ (where TTC $=$ actual time to contact at target disappearance; $T_{r}=$ time of response; $\alpha$ and $c$ are constants not equal to zero), describes the data well (Yakimoff, Bocheva, \& Mitrani, 1987; Yakimoff, Mateeff, Ehrenstein, \& Hohnsbein, 1993). When the target does not move with constant speed, such a model is not appropriate (see below). If the linear model is applied to data from experiments using direct-approach PM tasks, it is found that at a target disappearance TTC of $300 \mathrm{msec}$ observers would be predicted to consistently underestimate TTC by about $100 \mathrm{msec}$ and errors as large as $200 \mathrm{msec}$ or more would be expected.

The results of Whiting and colleagues do not conform to this expectation. Whiting's subjects were required to catch balls with one hand after the lights had been turned out (Sharp \& Whiting, 1974; Whiting et al., 1970; Whiting \& Sharp, 1974), a task that requires a temporal accuracy of $30 \mathrm{msec}$ or less (Alderson et al., 1974). Catching was reliably performed provided the lights were turned out not much more than $300 \mathrm{msec}$ before the catch was effected, implying accurate TTC estimation with a standard deviation less than $30 \mathrm{msec}$. Catching movements tend to be initiated about $300 \mathrm{msec}$ before contact (Alderson et al., 1974); thus, in the Whiting studies, successful performance was possible when response initiation began at around the time of target disappearance.

These results indicate that when the response is initiated close to the moment of disappearance, timing accuracy is good; if there is a significant delay, accuracy is poor. There is, however, a problem with this interpretation: the response in a PM task is an indication of temporal coincidence, whereas the "response" in the Whiting studies was an actual interception (catch) of the moving target. It is known that the variability (standard deviation of response times) of responses in CA tasks is some five or six times greater than that observed in IAs performed under the same stimulus conditions (Bootsma, 1989; McLeod et al., 1985; Tresilian, 1994a). Nevertheless, in Whiting's studies if the target disappeared much more than $300 \mathrm{msec}$ before it reached a catchable posi- 
tion, performance of the catching task became virtually impossible.

The interpretation that the time of disappearance relative to the response initiation time is crucial is supported by results reported by Yakimoff et al. (1993), who state that the linear model, which is successful for accounting for data obtained when the target disappears at a TTC larger than the buttonpress response time (TTCs range from minima of about $400 \mathrm{msec}$ to maxima of about $10 \mathrm{sec}$ ), cannot be successfully applied to data obtained when the target disappearance TTC is very short, $200 \mathrm{msec}$ or less (they refer to their results published in Acta Psychologica et Pharmacologica Bulgarica). This failure of the otherwise successful model may be interpreted as having been due to the observers' responses being initiated at around the time of target disappearance. Note, if the response is initiated at or before target disappearance, a PM task reduces to a standard CA task.

We may propose that the PM task involves a cognitive process that does something along the following lines: a clock process is used to count out the initially estimated TTC, such that when a time equal to this TTC has elapsed (minus the time taken to cause the button to be pressed), buttonpressing can be initiated. The large variability observed in PM tasks would then be due, in part at least, to the inherent variability in the clocking process. Another factor that is likely to influence the variability in response times is the uncertainty the observer has about whether the time of the response was correct or not (this is true for virtually all CA tasks). In a natural IA, the performer knows whether response timing was sufficiently accurate, is informed about it directly (the catch is missed or fumbled), and has information available about how to improve things. This is probably not the case in the PM task: the performer can usually only be told that he or she was too early or too late in responding and by how much (e.g., in milliseconds); such information may be insufficient for achieving precision timing.

\subsection{Long Viewing Periods Implicate Cognitive Operations in PM Tasks}

The tau hypothesis supposes that timing fast IAs incorporates the constant velocity approximation since the TTC extraction process (which uses only first-order TTC information, see above) is coupled directly to the motor controller. If true, there will be predictable patterns of performance when the target velocity is not constant. Although there is no firm, direct evidence on this matter (see Tresilian, 1993), existing observations of the interceptive timing appear to be consistent with this idea (Bootsma \& van Wieringen, 1990; Lee \& Reddish, 1981; Lee et al., 1983; McLeod et al., 1985; Tresilian, 1994a).

The constant velocity approximation has a certain plausibility because of the speed of processing required in many IAs (due to their brief execution and information pick-up times). Often, only a few hundred milliseconds are available to pick up the information and make the relevant movements-for such brief actions not only would acceleration estimates probably be unreliable, if available at all (see below), but also unnecessary since the effects of accelerations of terrestrial magnitudes (one gravity or less) over such short periods of time will often be negligibly small (see, e.g., Lee et al., 1983; Tresilian, 1994a).

The question of whether useful target acceleration estimates can be obtained visually can be addressed by considering the recent work of Werkhoven, Snippe, and Toet (1992), which has confirmed Gottsdanker's early conclusion that optic accelerations are not perceived directly but are inferred from changes in perceived velocity (Gottsdanker, 1952; Gottsdanker, Frick, \& Lockard, 1961). Werkhoven et al. measured speed modulation thresholds for a small moving visible target. They inferred from the results that the human visual system detects accelerations by monitoring the variance of a temporally filtered speed signal over a relatively long time period ( $>100 \mathrm{msec}$ ). Werkhoven et al. concluded that the visual system does not detect accelerations directly (i.e., it does not measure the time derivative of image velocity). Since the viewing period in many fast IAs is very short, there is unlikely to be sufficient time to obtain a useful acceleration estimate. Moreover, in order to usefully incorporate acceleration into a computation of TTC, not only its presence but also its value needs to be determined-despite plenty of psychophysical evidence that people can visually detect image acceleration (e.g., Babler \& Dannemillar, 1993; Calderone \& Kaiser, 1989; Regan, Kaufman, \& Lincoln, 1986; Werkhoven et al., 1992), there is no evidence that its value can be determined. This all supports the idea that the purely perceptual TTC extraction process, which is the source of timing information for IAs, does not take target acceleration into account.

Processes involved in PM tasks may be able to take acceleration into account by making use of observations that the velocity is changing. The reasons for supposing this are twofold. First, the visuomotor coupling is not the same in PM tasks as it is in IAs (as argued above) and is likely to involve the cognitive visual system. Second, the viewing periods are typically long (of the order of seconds rather than hundreds of milliseconds), which would give the system time to use the changing output of lowlevel "first-order" mechanisms to take accelerations into account. Therefore, it might be expected that while the performance of IAs conforms to the constant velocity approximation, performance in PM tasks does not. This is indeed what has typically been found (Jagacinski, Johnson, \& Miller, 1983; Rosenbaum, 1975; Runeson, 1975).

Rosenbaum (1975), for example, studied performance in the following PM task. A target moved along a straight trackway and, at some point during its motion, disappeared behind a screen. A marker, the same width as the target, was positioned on the screen, and the observer was required to press the button on a response box at the same moment as the target passed behind the 
marker. Performance when the target accelerated at a constant rate was not consistent with observers making a constant velocity approximation but indicated that observers were taking the target's acceleration into account. Other researchers have reported that accelerations are taken into account in extrapolating trajectories of disappearing targets, though the "cognitive model" used for extrapolation may differ from that appropriate for describing the target's actual motion (Jagacinski et al., 1983; Runeson, 1975).

\subsection{Generality of Results From Prediction-Motion Tasks}

To what extent do results from PM tasks generalize to IAs? Since it has been argued that quite different perceptual processes control responding in fast IAs and PM tasks, it would appear that results from the latter cannot readily be used to draw conclusions about the former. Although it has been proposed that the same type of information is available in both classes of task (first-order TTC information; see Figure 1), it is not known what kind of transformations and additions to this information are made in PM tasks.

Nevertheless, only two types of cognitive operation have been identified: the clocking process in motion extrapolation and a process that builds a cognitive model of target motion (or of how TTC is changing) and uses this in extrapolating motion and estimating TTC.' These processes are operative when there is an interval larger than the visuomotor delay between target disappearance and response time and when there is a long viewing period (in the order of seconds). In these conditions, one obtains results that are very different from those obtained in fast IAs. It is, as yet, unclear what happens if the target viewing period for a fast IA is extended to several seconds. According to the hypothesis proposed above, a highly skilled act is under the control of a direct perception-action linkage, and so cognitive modeling processes, which are implicated in the responses in PM tasks, would not be expected to influence performance. Slow actions that involve temporal estimation, such as crossing the street in the face of oncoming traffic, may not employ a direct perception-action coupling and so may be influenced by cognitive models of the trajectories of moving objects.

One final point that has been briefly mentioned but deserves further comment is the difference in the type of response in PM tasks and IAs. PM tasks typically involve indicating temporal coincidence with a buttonpress, whereas IAs typically involve physically contacting the moving target. It is known that the variability of temporal coincidence indications (in CA tasks, which do not involve target disappearance) is far greater than that of interceptive responses (Bootsma, 1989; McLeod et al., 1985; Tresilian, 1994a). There are at least two possible reasons for this. First, temporal coincidence anticipations are less well practiced than are IAs, and it is known that response variability tends to decrease with practice (under conditions of consistent feedback; Ack- erman, 1988; Schneider \& Shiffrin, 1977). Second, as noted earlier, the feedback available in CA tasks is not as specific as that available for interceptions, and it may not be possible to refine temporal precision in the former type of task to the same degree as in the latter. There is no evidence, however, that making a coincidence indication is itself a necessary or sufficient condition for involvement of the cognitive route for linking perceptual and response processes.

It may be concluded that it is not, in general, possible to use PM tasks to test hypotheses about the information used in fast IAs. As shown above, it is not possible to conclude from the results of Rosenbaum (1975) or Jagacinski et al. (1983) that target accelerations are taken into account in fast IAs. Moreover, empirical extrapolation models that fit data from PM tasks when the interval between target disappearance and response is large $(>400 \mathrm{msec})$ break down when the interval is smaller than the visuomotor delay (Yakimoff et al., 1993) - that is, when the PM task effectively becomes a standard CA task. However, if a particular source of first-order TTC information can be used to control the response in a PM task, there is no reason to suppose that it cannot be used in an IA, and vice versa. Indeed, such demonstrations provide a strong indication that the source of information involved in one type of task (e.g., a PM task) can be used in the other type (an IA). However, this is just a pointer, additional evidence that the information can be used in the other type of task will be required.

\section{RELATIVE JUDGMENT TASKS}

\subsection{Absence of a Timing Requirement in RJ Tasks}

$\mathrm{RJ}$ tasks do not require a timed response to be made; for this reason, TTC information is not necessary for making the judgment if other information is available to tell the observer which target will arrive first at the contact point. Any cue that enables the observer to make this discrimination provides a valid means for performing an RJ task. In addition, there is no reason for supposing that a person performing an RJ task will automatically use TTC information to solve it. It appears that perceptual systems are opportunistic and rarely behave as the researcher would like: faced with tasks that are unfamiliar or that fail to activate a previously developed perceptuomotor linkage, the perceptual systems will use whatever information is available in an unknown and possibly haphazard fashion (see, e.g., Ramachandran, 1990). Experience results in refinement of use and a "homing in" on the most appropriate source(s) of information (i.e., those that satisfactorily get the job done).

In studying perceptual discriminations, it is usual to design the different stimuli such that there is only one source of information (or cue) that distinguishes between them. If this were the case for RJ tasks, then we could be fairly certain that the observers were using the information we were interested in to make their discriminations (once they had become proficient). There 
is some reason to be confident that TTC information is used in RJ tasks involving direct or approximately direct (simulated) approach of the target to the observer, and so continuous magnification of the target's image (e.g., Regan \& Hamstra, 1993; Simpson, 1988; Todd, 1981). The only useful information for making the discrimination appears to be the tau values of the targets. That this information is used by observers is indicated by the fineness of discriminations and the independence of judgments from other possible factors (Regan \& Hamstra, 1993; Simpson, 1988; Todd, 1981).

A recent study by Law et al. (1993) illustrates that when other cues are present in an RJ task, subjects may not use TTC information at all. This study will be described in some detail since the interpretation of the results given here is somewhat different to that offered by the authors.

The results of Law et al.'s study are interesting because observers did not, on the whole, appear to use TTC information in the performance of a TTC RJ task. Two small targets (the symbols " 0 " and "l") moved across the screen toward contact points (the symbol "+") in a variety of configurations (Figure 3 ). The task was to indicate which target would reach its contact point first.

Observers were new to the experimental task and received only nine practice trials. There is no a priori reason to suppose that the observers had available a linkage between a TTC extraction device and the decision process. It is quite possible that during performance of the experimental trials, subjects were engaged in a learning process in which various sources of information were being "tried out" as possible means of achieving satisfactory performance. Given that observers were not provided with feedback of errors, the learning process was unlikely to converge on a satisfactory solution.

The results support this proposal. Observers appeared to notice that certain trials involved targets that moved at the same speed, which meant that the target closer to its contact point when the display terminated was the one that would arrive first. Clearly, this would be a simple judgment in Configurations 1 and 2 (Figure 3). The results of Law et al.'s Experiment 1 show that when the targets moved at the same speed, observers usually made the correct judgment and that Configurations 1 and 2 were easiest. When the targets moved at different speeds, the closer target was the first to arrive on only $50 \%$ of trials. However, observers tended to use the "closer is first" rule in these trials: in Experiment 1, on the $50 \%$ of trials when closer was first to arrive, observers were correct on about $94 \%$ of trials. On the $50 \%$ of trials when closer was not first, observers were correct on $32 \%$ of trials (chance performance is $50 \%$ ). This finding was confirmed in Experiments 3 and 4.

These results are consistent with observers' simply applying the "closer is first" rule on all trials, as Law et al, themselves conclude. The observers may have been told that the task was an arrival time judgment task, but they did not use TTC information to solve it. In the ab- sence of feedback, observers seem to have hit upon the strategy of using the "closer is first" rule and apparently virtually ignored target-speed information. There was some evidence that speed information was sometimes used, but only to a small degree and possibly not by all subjects (Experiment 4).

Had observers been provided with feedback there would have been information available to guide them in a search for an appropriate information source to solve the task. It would be expected, therefore, that feedback would improve performance, and observers would tend to use TTC information rather than applying the "closer is first" rule to all trials. In fact, Law et al. (1993) report results of another study of theirs (Fischer, Hickey, Pellegrino, \& Law, 1994) that confirm this expectation. They do report, however, that the "closer is first" rule persists. This is not surprising since the "closer is first" rule works on a significant proportion $(50 \%$ or more) of trials, and it may be extremely difficult to eradicate inappropriate use of it.

It is interesting to note that in PM tasks observers are quite able to take both target position and velocity into account when the target moves in a plane parallel to the observer's frontal plane, as attested by the fact that results are found to depend upon TTC and not distance from the contact point (e.g., Reynolds, 1968; Yakimoff et al., 1993). This also appears to be true when there are two targets moving toward some "collision" point, provided that alternative cues such as those present in Law et al.'s study are removed (Bootsma \& Oudejans, 1993).

\subsection{Cognitive Factors in Relative Judgment 'Tasks}

Law et al.'s results demonstrate that if the mechanisms of TTC perception are to be studied using an RJ task, then it is important to ensure that alternative cues are eliminated. If this is done, $\mathrm{RJ}$ tasks have the advantage that the time interval between target disappearance and

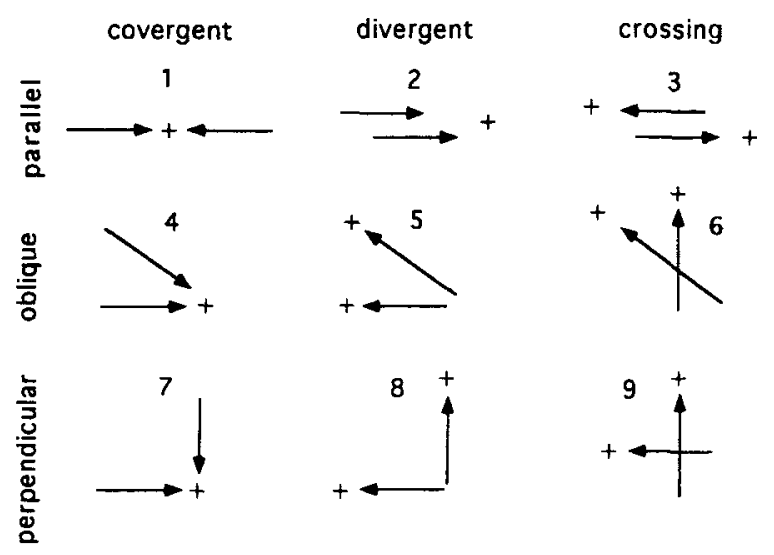

Figure 3. Various target movement (arrows) and contact point ("+") configurations used in Law et al.'s experiments. From "Perceptual and Cognitive Factors Governing Performance in Comparative Arrival Time Judgments," by D. J. Law et al., 1993, Journal of Experimental Psychology: Human Perception \& Performance, 19, p. 1185. Copyright 1993 by the American Psychological Association. Adapted by permission. 
response initiation can be minimized and perhaps virtually eliminated by encouraging observers to respond either while the targets are still visible or as soon as possible after their disappearance. Typically, observers respond quickly following disappearance, and quite precise discrimination of TTC differences between two simulated targets (approaching the observer with constant velocity) has been reported (Regan \& Hamstra, 1993; Simpson, 1988; Todd, 1981). Observed discrimination performance is much better than the results of PM tasks would lead one to expect. For example, Regan and Hamstra (1993) reported a discrimination threshold of $7 \%-13 \%$ for displays terminating between 1 and $4 \mathrm{sec}$ before contact, which translates into a reliably detectable TTC difference of $280-520 \mathrm{msec}$ at a termination TTC of $4 \mathrm{sec}$ (Todd, 1981, reported even better discrimination performance). At a 4-sec termination, TTC responses in PM tasks have a standard deviation of 1-2 sec (1.8 sec in Schiff \& Detwiler's, 1979, study).

It is plausible to suppose that performance of wellpracticed RJ tasks, where TTC is the only reliable cue, could involve a "direct" coupling of perception and response via the motor visual system, especially if the viewing period is brief. It certainly seems possible that $\mathrm{RJ}$ tasks minimize the influence of cognitive factors in TTC estimation. DeLucia (1991), however, has found evidence of what she calls a "size-arrival effect" in an RJ task: observers tended to judge the larger of two expanding squares as nearer in time when the smaller was in fact the nearer as defined by its visual tau value. This effect has recently been replicated in an avoidance task in which observers were required to "jump" over a simulated approaching target in a video-game-style task (DeLucia \& Warren, 1994). DeLucia interpreted the size-arrival effect as indicating that observers may heuristically use quantities, such as image size, which have weak correlations with nearness in time, to infer nearness in time ${ }^{2}$ and therefore use such quantities as information about TTC.

According to the scheme being advocated here, operations of the kind DeLucia suggests implicate the cognitive route from perception to response and may, therefore, provide evidence for cognitive operations in the performance of RJ tasks that are practiced and provide no reliable cues to accurate performance other than the available TTC information (visual tau). Note that DeLucia (1991) reported that if the tau value is small $(<700 \mathrm{msec})$ when the observer responds, the sizearrival effect is not present. This result is consistent with the idea that at long TTCs, estimates of TTC are based not only upon TTC information but also upon heuristic cues (such as image size) that have some correlation with TTC: these heuristic cues are not used at the short TTCs relevant for the control of IAs. It seems likely that such heuristics, if used in RJ tasks at long TTCs as DeLucia's result suggests, would also be used in PM tasks. There is, however, no data that directly address this issue.
A tentative conclusion would therefore be to suggest that RJ tasks can enable one to study noncognitive processing of TTC information - that is, to study the operation of the TTC processor shown in Figure 1 (right panel). However, one should be careful to avoid the presence of those display features that could provide reliable cues for solving the task but are not sources of TTC information. It was argued above that if such cues are present, subjects are likely to use them, because RJ tasks are not timing tasks and so do not automatically implicate a linkage between the TTC processor and the response. This section will be concluded with a discussion of a recent study reported by Kaiser and Mowafy (1993). The data in this study indicate that when an additional cue is present that can be used to make an RJ (but does not supply TTC information), it is used by observers. In the absence of this cue, performance can be accounted for by global tau information only; in the presence of the cue, performance is rather better than global tau information might suggest is possible.

Kaiser and Mowafy examined human observers' abilities to make relative TTC judgments using global optic tau information. Observers were asked to indicate which of two colored targets within a flow field-defined by an additional number of uncolored moving pointswould pass their observation point first. This is a discrimination of relative time to passage (TTP). Global tau is defined for the optical velocity field (= the translational component of the image velocity field) induced by an observer's movement through an environment. The global tau $\left(\tau_{G}\right)$ value for the image of a point on a surface can be defined as the relative rate of dilation of the distance, $r$, of the point's image from the flow field's focus of expansion as measured on the image plane, $\tau_{G}=r / r=\tau(r)$ (see Lee, 1980; Tresilian, 1990). In the case of constant velocity, $\tau_{G}$ is equal to the time remaining before the surface point crosses the plane perpendicular to the observer's direction of motion and passing through the center of projection (the TTP).

In their Experiment 1A, Kaiser and Mowafy examined two conditions: in one, there was a relative motion cue that provided information relevant to determining which target would pass first; in the other condition, this cue was absent. The relative motion cue did not provide information about when the targets would pass the observer (see Kaiser \& Mowafy, 1993, p. 1032). When this cue was present, results were consistent with observers' use of it and rather better than performance when the cue was absent (see Kaiser \& Mowafy, 1993, Figure 4A, p. 1032). In what follows, the condition in which the relative motion cue was absent is analyzed; global tau was presumably the only available information relevant to making the discrimination.

Kaiser and Mowafy's observers showed chance discrimination when the TTP difference between the two targets was about $200-250 \mathrm{msec}$ (display terminated when the "nearer" target was $2 \mathrm{sec}$ from passing the observer). The $75 \%$ correct point was found to be some- 
where between 500 and $700 \mathrm{msec}$ in all conditions. Using the analysis developed in an earlier paper (Tresilian, 1993), one can inquire whether this result would be expected if the main source of uncertainty in making the discrimination arises only from uncertainty about the location of the focus of expansion (FOE) of the stimulus velocity field.

It can be shown (Tresilian, 1993, Appendix C) that if the uncertainty in the location of the FOE is $\epsilon_{0}$ (which can be identified as the threshold for FOE location), then the corresponding uncertainty in estimating TTP using global tau (assuming that the uncertainty in estimating the FOE dominates) is given by $Z^{2} \tan \epsilon_{0} / R V$, which follows from Equation C4 in Tresilian (1993, p. 680). Thus, the uncertainty in the global tau estimate deriving from uncertainty in FOE location depends not only upon the FOE uncertainty itself $\left(\epsilon_{0}\right)$ but upon other parameters, $V$ (speed), $Z$ (distance of target from observer), and $R$ (vertical displacement of target from observer's direction of motion). Note that the dependency on these parameters arises here only because of the uncertainty in FOE location. In practice, it may also depend upon these parameters because of factors like uncertainty in image velocity measurement and retinal eccentricity effects, but these are ignored here for simplicity.

The expected TTP difference threshold for global tau can now be estimated. Notice that the threshold will depend upon the values of $V, Z$, and $R$ involved. Suppose that there are two targets, as in Kaiser and Mowafy's (1993) Experiment 1: for Target $1, Z=Z_{1}, R=R_{1}$, and $V=V_{1}$; for Target 2, the respective values are $Z_{2}, R_{2}$, and $V_{2}$. We now assume that the TTP difference threshold, $\Theta_{T}$ (assuming that the uncertainty in locating the FOE is the overwhelming source of uncertainty in measuring global tau) is given by

$$
\Theta_{T}=\frac{1}{2}\left(Z_{1}^{2} \tan \epsilon_{0} / R_{1} V_{1}+Z_{2}^{2} \tan \epsilon_{0} / R_{2} V_{2}\right) .
$$

In Kaiser and Mowafy's (1993) Experiment 1A, the speed $(V)$ was approximately $1.5 \mathrm{~m} / \mathrm{sec}, R$ could take the values $0.125,0.254,0.381$, and $0.508 \mathrm{~m}$, and the depth difference $\left(Z_{1}-Z_{2}\right)$ could take the values $0.381,0.762$, 1.143 , and $1.524 \mathrm{~m}$. The value of $\epsilon_{0}$ may be taken to be equal to the threshold for location of the direction of locomotion from an optic velocity field. This threshold was measured by Warren and colleagues from a stimulus display similar to that used by Kaiser and Mowafy and was found to be about $1^{\circ}$ of visual angle (Warren \& Hannon, 1990; Warren, Morris, \& Kalish, 1988). Assuming an FOE location threshold of $1^{\circ}$, one can compute the quantity $\Theta_{T}$ for the complete set of parameters for Kaiser and Mowafy's experiment. The computation was carried out assuming that the TTP estimates obtained immediately before target disappearance (i.e., at a TTP of $2 \mathrm{sec}$ for the nearer target) determine $\Theta_{T}$. The results are presented in Table 2 .

The expectation is that the results presented in Table 2 should be at least as good as, if not better than, performance of Kaiser and Mowafy's subjects. Kaiser and Mowafy did not measure threshold performance; they averaged over all conditions with the same TTP difference. However, if we average the threshold over conditions with the same TTP difference, we obtain $0.48 \mathrm{sec}$ as the average at a TTP difference of $0.25 \mathrm{sec}, 0.52$ at $0.5 \mathrm{sec}, 0.58$ at $0.75 \mathrm{sec}$, and 0.64 at $1.00 \mathrm{sec}$, implying that the "mean threshold" in Kaiser and Mowafy's experiment should be greater than $0.5 \mathrm{sec}$ but less than $0.75 \mathrm{sec}$ (at $0.5 \mathrm{sec}$, the threshold is greater than the TTP difference; at $0.75 \mathrm{sec}$, the threshold is less than the difference). The $75 \%$ correct point in the data reported by Kaiser and Mowafy (1993, Figures 4A, 4B, and 4C, p. 1032) is indeed in the expected range. Note that in the condition where the relative motion cue was present (Figure 4A, p. 1032), the $75 \%$ correct point is in the range $0.25-0.5 \mathrm{sec}$, which is better than that expected from global tau.

Thus, it could be tentatively concluded that Kaiser and Mowafy's (1993) results are consistent with the estimates of FOE location accuracy reported by Warren and colleagues in the conditions where the relative motion cue was absent. If this is acceptable, it indicates that

Table 2

Estimated Time-to-Contact Difference "Thresholds" (in Seconds) for the 40 Possible Distinguishable Stimulus Configurations Calculated as Described in the Text

\begin{tabular}{ccccccc}
\hline \multicolumn{2}{l}{ Target Distance } & & \multicolumn{4}{c}{ "Thresholds" } \\
\cline { 1 - 5 } \cline { 5 - 6 }$R_{1}$ & $R_{2}$ & & 0.25 -sec ATD & 0.50 -sec ATD & 0.75 -sec ATD & 1.00 -sec ATD \\
\hline 0.125 & 0.125 & 0.95 & 1.08 & 1.22 & 1.37 \\
0.125 & 0.254 & 0.68 & 0.74 & 0.81 & 0.89 \\
0.125 & 0.381 & 0.60 & 0.64 & 0.68 & 0.73 \\
0.125 & 0.508 & 0.55 & 0.58 & 0.62 & 0.65 \\
0.254 & 0.254 & 0.48 & 0.53 & 0.60 & 0.68 \\
0.254 & 0.381 & 0.38 & 0.42 & 0.47 & 0.52 \\
0.254 & 0.508 & 0.34 & 0.37 & 0.40 & 0.44 \\
0.381 & 0.381 & 0.32 & 0.35 & 0.40 & 0.45 \\
0.381 & 0.508 & 0.27 & 0.30 & 0.33 & 0.37 \\
0.508 & 0.508 & 0.24 & 0.27 & 0.30 & 0.34 \\
\hline
\end{tabular}

Note-Target distance, in meters, is distance from line of motion. ATD, arrival time difference, is the difference between the times that the two targets pass the observer. 
the main source of information used to make the relative judgments in these conditions was global tau and that the main source of uncertainty in estimating global tau is the uncertainty in FOE location. However, a number of possible factors were not taken into account, and a number of simplifying assumptions were made in the analysis presented here. Nevertheless, the result is suggestive and illustrates a mode of analysis that could be used in analyzing results from RJ tasks. This kind of analysis could be helpful in teasing apart the basic perceptual sensitivities, upon which interceptive timing is hypothesized to rest, from subsequent "cognitive" operations.

\section{CONCLUSIONS}

There are at least three classes of task that are likely to involve TTC information: (1) coincidence anticipation (CA) tasks (which encompass PM tasks), (2) relative judgement (RJ) tasks, and (3) interceptive actions (IAs). We examined important differences between these types of task and inquired whether results from PM and RJ tasks can be generalized to IAs.

A revised version of Lee's tau hypothesis for the timing of fast IAs was proposed as an account of what perceptual information and information processing is involved in interceptive timing. Fast IAs are characterized by their brief execution times and relatively short targetviewing times, and they are typically highly practiced and "automatic." The following hypothesis was proposed: Fast IAs involve the "motor visual system" described by Bridgeman and Goodale, whereas PM and RJ tasks may involve the "cognitive visual system." This hypothesis implies that it is not, in general, justified to draw conclusions about the processes operating in one type of task from results obtained using a different task. Nevertheless, if a PM or an RJ task approximates an IA in three respects (brief viewing time, TTC information available at response initiation-a fortiori, at small TTCs - and high level of practice), then the influence of cognitive processes is minimized and there is the possibility that they may, in some circumstances, be eliminated altogether.

A variety of experimental results obtained using PM and RJ tasks were reviewed. These results are consistent with the proposed hypothesis, which therefore serves as a convenient means for organizing data obtained using a variety of different paradigms, stimuli, and task conditions. The following general conclusions were drawn:

(1) When the TTC is large at target disappearance and the viewing period is relatively long, subject responses provide evidence for cognitive operations. In PM tasks, there is evidence for a "clocking" process for metering out time elapsed after target disappearance and for a process modeling the trajectory of the moving target. In $\mathrm{RJ}$ tasks, there is evidence of the use of heuristics based on such factors as image size (DeLucia, 1991).

(2) In an RJ task, the observer only needs to decide which target will arrive first; no timed response is re- quired. There may be a variety of cues that could be reliably used to make the judgment but that do not inform about when a target will arrive. It appears that when such alternative cues are available, observers use them (e.g., Kaiser \& Mowafy, 1993; Law et al., 1993).

(3) It does not appear that the buttonpressing response, as opposed to an actual interceptive or avoidance movement, is sufficient to lead to cognitive influences of the kind discussed here. Practice, length of viewing period, length of TTC when response is initiated, and availability of perceptual information when the response is initiated appear to be the crucial factors.

It may be possible, therefore, to use PM and RJ tasks to study noncognitive TTC processing by ensuring that the response is initiated at short TTCs, that the target viewing period is short, that any gap between target disappearance and response initiation is small or absent (in the latter case, PM tasks reduce to standard CA tasks), and that the subject has plenty of practice. In any event, one should be careful not to generalize, without qualification, results from one type of task to another.

To conclude, a tentative hypothesis has been put forward for understanding TTC perception and the processes involved in the different types of task that have been used to study perceptual timing skills. This hypothesis provides a unified interpretation of many empirical results and is consistent with available data. It details the type of information processing involved in deriving TTC information from the stimulus input and the kinds of subsequent processing operations implicated in different types of task. The details are open to empirical test and refinement, as is clear from the extensive discussion provided.

\section{REFERENCES}

ACKerman, P. L. (1988). Determinants of individual differences during skill acquisition: Cognitive abilities and information processing. Journal of Experimental Psychology: General, 117, 288-318.

Alderson, G. K., Sully, H., \& Sully, D. (1974). An operational analysis of a one-handed catching task using high speed photography. Journal of Motor Behavior, 6, 217-226.

ANDERSON, J. R. (1982). Acquisition of cognitive skill. Psychological Review, 89, 369-406.

ARBIB, M. A. (1981). Perceptual structures and distributed motor control. In V. B. Brooks (Ed.), Handbook of physiology: Section 1. The nervous system: Vol. 2. Motor control (pp. 1449-1480). Bethesda, MD: American Physiological Society.

BABLER, T. G., \& DANNEMillaR, J. L. (1993). Role of image acceleration in judging landing location of free-falling projectiles. Journal of Experimental Psychology: Human Perception \& Performance, 19, 15-31.

BaHill, A. T., \& Karnavas, W. J. (1993). The perceptual illusion of baseball's rising fastball and breaking curveball. Journal of Experimental Psychology: Human Perception \& Performance, 19, 3-14.

BARGH, J. A. (1992). The ecology of automaticity: Toward establishing the conditions needed to produce automatic processing effects. American Journal of Psychology, 105, 181-199.

Bootsma, R. J. (1989). Accuracy of perceptual processes subserving different perception-action systems. Quarterly Journal of Experimental Psychology, 41A, 489-500.

Bootsma, R. J., \& Oudejans, R. (1993). Visual information about time to collision between two objects. Journal of Experimental Psychology: Human Perception \& Performance, 19, 1041-1052. 
Bootsma, R. J., \& van Wieringen, P. C. (1990). Timing an attacking forehand drive in table tennis. Journal of Experimental Psychology: Human Perception \& Performance, 16, 21-29.

Bridgeman, B., KirCh, M., \& Sperling, A. (1981). Segregation of cognitive and motor aspects of visual function using induced motion. Perception \& Psychophysics, 29, 336-342.

Bridgeman, B., \& Lewis, S. (1976). How the eye knows where the world is. Neuroscience Abstracts, 25, 277.

Bridgeman, B., Lewis, S., Heit, G., \& Nagle, M. (1979). The relationship between cognitive and motor-oriented systems of visual position perception. Journal of Experimental Psychology: Human Perception \& Performance, 5, 692-700.

Bruce, V., \& Green, P. (1985). Visual perception: Psychology, physiology and ecology. Hillsdale, NJ: Erlbaum.

Calderone, J. B., \& Kaiser, M. K. (1989). Visual acceleration detection: Effect of sign and motion orientation. Perception \& Psychophysics, 45, 391-394.

Cavallo, V., \& Laurent, M. (1988). Visual information and skill level in time-to-collision estimation. Perception, 17, 623-632.

DeLucia, P. R. (1991). Pictorial depth cues and motion-based information for depth perception. Journal of Experimental Psychology: Human Perception \& Performance, 17, 738-748.

Delucia, P. R., \& Warren, R. (1994). Pictorial and motion-based depth information during active control of self-motion: Size-arrival effects on collision avoidance. Journal of Experimental Psychology: Human Perception \& Performance, 20, 783-798.

Fischer, S. C, Hickey, D. T., Pellegrino, J. W., \& LaW, D. J. (1994). Strategic processing in dynamic spatial ability tasks. Learning \& Individual Differences, 6, 65-105.

FirTs, P., \& PosNeR, M. I. (1967). Human performance. Belmont, CA: Brooks/Cole

FODOR, J. (1983). The modularity of mind: An essay on faculty psychology. Cambridge, MA: MIT Press.

Goodale, M. A., \& JAKOBSON, L. S. (1992). Action systems in the posterior parietal cortex. Behavioral \& Brain Sciences, 15, 747.

Goodale, M. A., \& Milner, A. D. (1992). Separate visual pathways for perception and action. Trends in Neurosciences, 15, 20-25.

Goodale, M. A., Milner, A. D., Jakobson, L. S., \& Carey, D. P. (1991). A neurological dissociation between perceiving objects and grasping them. Nature, 329, 154-156.

Goodale, M. A., Pelisson, D., \& Prablanc, C. (1986). Large adjustments in visually guided reaching do not depend on vision of the hand or perception of target displacement. Nature, 320, 748-750.

GotTSDANKER, R. M. (1952). The accuracy of prediction motion. Journal of Experimental Psychology, 43, 26-36.

GotTSDANKER, R. M., FrICK, J., \& LOCKARD, R. B. (1961). Identifying the acceleration of visual targets. British Journal of Psychology, 52, 155-160.

Groeger, J. A., \& Brown, I. D. (1986). Motion perception is not direct with indirect viewing systems. In A. Gale, M. Freeman, C. Haselgrave, P. Smith, \& S. Taylor (Eds.), Vision in vehicles (pp. 27-34). Amsterdam: Elsevier.

HEUER, H. (1993). Estimates of time to contact based on changing size and changing target vergence. Perception, 22, 549-563.

Hofsten, C. von (1983). Catching skills in infancy. Journal of Experimental Psychology: Human Perception \& Performance, 9, 75-85.

Hofsten, C. voN (1987). Catching. In H. Heuer \& A. F. Sanders (Eds.), Perspectives on perception and action. Hillsdale, NJ: Erlbaum.

Hofsten, C. von, \& LeE, D. N. (1982). Dialogue on perception and action. Human Movement Science, 1, 125-138.

JAGACINSKI, R. J., JoHNSON, W., \& Miller, R. A. (1983). Quantifying the cognitive trajectories of extrapolated movements. Journal of Experimental Psychology: Human Perception \& Performance, 9 , 43-57.

KaISER, M. K., \& Mowafy, L. (1993). Optical specification of timeto-passage: Observers' sensitivity to global tau. Journal of Experimental Psychology: Human Perception \& Performance, 19, 1028 1040.

Lacovaniti, F., \& Maioli, C. (1989). The role of preparation in tun- ing anticipatory and reflex responses during catching. Journal of Neuroscience, 9, 134-148.

Law, D. J., Pellegrino, J. W., Mitchell, S., Fischer, S. C., McDonald, T. P., \& Hunt, E. B. (1993). Perceptual and cognitive factors governing performance in comparative arrival time judgments. Journal of Experimental Psychology: Human Perception \& Performance, 19, 1183-1199.

LEE, D. N. (1976). A theory of visual control of braking based on information about time to collision. Perception, 5, 437-459.

LEE, D. N. (1980). Visuo-coordination in space-time. In G. E. Stelmach \& J. Requin (Eds.), Tutorials in motor behavior (pp. 281295). Amsterdam: North-Holland.

LEE, D. N. (1992). Body environment coupling. In U. Neisser (Ed.) Ecological and interpersonal knowledge of the self. Cambridge Cambridge University Press.

LeE, D. N., Lishman, J. R., \& Thompson, J. (1982). Regulation of gait in long jumping. Journal of Experimental Psychology: Human Perception \& Performance, 8, 448-459.

LEE, D. N., \& REDDrSH, P. E. (1981). Plummeting gannets: A paradigm of ecological optics. Nature, 293, 293-294.

LEE, D. N., Reddish, P. E., \& RAND, D. (1991). Aerial docking by hummingbirds. Naturwissenschaften, 78, 526-527.

LEE, D. N., \& YoUNG, D. S. (1985). Visual timing of interceptive action. In D. Ingle, M. Jeannerod, \& D. N. Lee (Eds.), Brain mechanisms and spatial vision (pp. 1-30). Dordrecht: Martinus Nijhoff

LeE, D. N., Young, D. S., Reddish, P. E., Lough, S., \& Clayton, T (1983). Visual timing in hitting an accelerating ball. Quarterly Journal of Experimental Psychology, 35A, 333-346.

Logan, G. D., \& Cowan, W. B. (1984). On the ability to inhibit thought and action: A theory of an act of control. Psychological Review, 91, 295-327.

MCKeE, S. P. (1981). A local mechanism for differential velocity discrimination. Vision Research, 21, 491-500.

McLeod, P., McLaughlin, C., \& Nimmo-Smith, I. (1985). Information encapsulation and automaticity: Evidence from the visual control of finely timed actions. In M. Posner \& O. Marin (Eds.), $A t$ tention and performance $X I$ (pp. 391-406). Hillsdale, NJ: Erlbaum.

McLeod, R. W., \& Ross, H. E. (1983). Optic flow and cognitive factors in time-to-collision estimates. Perception, 12, 417-423.

Nakayama, K. (1994). James J. Gibson-An appreciation. Psychological Review, 101, 329-335.

RAMACHANDRAN, V. S. (1990). Visual perception in people and machines. In A. Blake \& T. Troscianko (Eds.), AI and the eye (pp. 2177). Chichester, UK: Wiley.

Regan, D. M. (1992). Visual judgements and misjudgements in cricket and the art of flight. Perception, 21, 91-115.

Regan, D. M., \& Hamstra, S. (1993). Dissociation of discrimination thresholds for time to contact and for rate of angular expansion. $V i$ sion Research, 33, 447-462.

Regan, D. M., Kaufman, L., \& Lincoln, J. (1986). Motion in depth and visual acceleration. In K.R. Boff, L. Kaufman, \& J. P. Thomas (Eds.), Handbook of perception and human performance: Vol 1 . Sensory processes and perception (pp. 19-1 to 19-46). New York: Wiley.

REYNOLDS, H. N. (1968). Temporal estimation in the perception of occluded motion. Perceptual \& Motor Skills, 26, 407-416.

Rosenbaum, D. A. (1975). Perception and extrapolation of velocity and acceleration. Journal of Experimental Psychology: Human Perception \& Performance, 1, 395-403.

Rosenblum, L. D., Wuestefeld, A. P., \& Saldana, H. M. (1993). Auditory looming perception: Influences on anticipatory judgments. Perception, 22, 1358-1514.

RUNESON, S. (1975). Visual prediction of collision with natural and nonnatural motion functions. Perception \& Psychophysics, 18, 261 266.

Savelsbergh, G. J. P., \& van Emmerik, R. E. A. (1992). Dynamic interactionism: From co-regulation to the mapping problem. Human Movement Science, 11, 443-451.

SCHIFF, W., \& DETWILER, M. L. (1979). Information used in judging impending collision. Perception, 8, 647-658. 
SCHIFF, W., \& OldaK, R. (1990). Accuracy of judging time to arrival: Effects of modality, trajectory, and gender. Journal of Experimental Psychology: Human Perception \& Performance, 16, 303-316.

SCHMIDT, R. A. (1982). More on motor programs. In J. A. S. Kelso (Ed.), Human motor behavior: An introduction (pp. 189-217). Hillsdale, NJ: Erlbaum.

SChNeIder, W., \& Shiffrin, R. M. (1977). Controlled and automatic human information processing: I. Detection, search and attention. Psychological Review, 84, 1-66.

SHARP, R., \& Whiting, H. T. A. (1974). Exposure and occluded duration effects in a ball-catching skill. Journal of Motor Behavior, $\mathbf{6}$, 139-147.

ShaRP, R., \& Whiring, H. T. A. (1975). Information processing and eye-movement behaviour in a ball-catching skill. Journal of Human Movement Studies, 1, 124-131.

Shaw, B. K., MCGowan, R., \& Turvey, M. T. (1991). An acoustic variable specifying time-to-contact. Ecological Psychology, 3, 253261.

Simpson, W. A. (1988). Depth discrimination from optic flow. Perception, 17, 497.512.

ToDD, J. T. (1981). Visual information about moving objects. Journal of Experimental Psychology: Human Perception \& Performance, 7, 795-810.

Tresilian, J. R. (1990). Perceptual information for the timing of interceptive action. Perception, 19, 223-239.

Tresilian, J. R. (1993). Four questions of time-to-contact: A critical analysis of research into interceptive timing. Perception, 22, 653680.

Tresilian, J. R. (1994a). Approximate information sources and perceptual variables in interceptive timing. Journal of Experimental Psychology: Human Perception \& Performance, 20, 154-173.

Tresilian, J. R. (1994b). Continuous and preprogrammed regulation of interceptive action by visual time-to-contact information: Lee et al. (1983) revisited. Manuscript submitted for publication.

Tresilian, J. R. (1994c). Perceptual and motor processes in interceptive timing. Human Movement Science, 13, 335-373.

TreVARTHEN, C. B. (1968). Two mechanisms of vision in primates Psychologische Forschung, 31, 299-337.

Turvey, M. T., \& Carello, C. (1986). The ecological approach to perceiving-acting. Acta Psychologica, 63, 133-155.

UNGERLEIDER, L. G., \& MishKIN, M. (1982). Two cortical visual systems. In D. Ingle, M. A. Goodale, \& R. J. W. Mansfield (Eds.), The analysis of visual behavior. Cambridge, MA: MIT Press.

Wallace, S. A., Stevenson, E., Weeks, D. L., \& Kelso, J. A. S. (1992). The perceptual guidance of grasping a moving object. Human Movement Science, 11, 691-716.

WARREN, W. H., \& HANNON, D. J. (1990). Eye movements and optical flow. Journal of the Optical Society of America A, 17, 160-170.

WARren, W. H., Morris, M. W., \& Kalish, M. (1988). The perception of translational heading from optical flow. Journal of Experimental Psychology: Human Perception \& Performance, 14, 646-660.
WARrEN, W. H., Young, D. S., \& LeE, D. N. (1986). Visual control of step length during running over irregular terrain. Journal of Experimental Psychology: Human Perception \& Performance, 12, $259-$ 266.

Werkhoven, P., Snippe, H. P., \& Toet, A. (1992). Visual processing of optic acceleration. Vision Research, 32, 2313-2329.

Whiting, H. T. A., Gill, E. B., \& Stephenson, J. (1970). Critical time intervals for taking in flight information in a ball-catching task. $\mathrm{Er}$ gonomics, 13, 265-272.

WHITING, H. T. A., \& SHARP, R. (1974). Visual occlusion factors in a discrete ball-catching task. Journal of Motor Behavior, 6, 11-16.

YAKIMOFF, N., BocheVA, L., \& Mitrani, L. (1987). A linear model for the response time in motion prediction. Acta Neurobiologiae Experimentalis, 47, 55-62.

Yakimoff, N., MateefF, S., Ehrenstein, W. H., \& Hohnsbein, J. (1993). Motion extrapolation performance: A linear model approach. Human Factors, 35, 501-510.

Young, D. E., \& SChMidT, R. A. (1990). Units of motor behavior: Modifications with practice and feedback. In M. Jeannerod (Ed.), Attention and performance XIII: Motor representation and control (pp. 763-795). Hillsdale, NJ: Erlbaum.

\section{NOTES}

1. It should be stressed that identification of trajectory modeling processes as purely cognitive derives from the constant velocity approximation hypothesis for fast interceptive actions. If this hypothesis is false (cf. Lacquaniti \& Maioli, 1989), then extrapolated trajectories that take accelerations into account may reflect the operation of precognitive basic perceptual precesses.

2. I have elsewhere claimed (Tresilian, 1994c) that the size-arrival effect reported in DeLucia (1991) might have been due to a conflict between monocular and binocular cues to TTC. This could not actually have been the case since observers in DeLucia's study viewed the displays monocularly. I had confused the viewing conditions in DeLucia (1991) and a later paper (DeLucia \& Warren, 1994). In the latter paper, the conflict between monocular and binocular cues suggested in Tresilian (1994c) could be the explanation for the size-arrival effect. If so, this would mean that the explanation of the size-arrival effects observed by DeLucia are different in different tasks. The effects reported by DeLucia (1991) in an RJ task would be a result of perceptualresponse linkage via the cognitive visual system as described in the text (note that the size-arrival effect disappears at short TTCs as would be expected according to this hypothesis). The task employed by DeLucia and Warren (1994) approximates a natural IA and would hence be hypothesized to involve the motor visual system. The explanation for the size-arrival effect could then be the cue conflict explanation I proposed in Tresilian (1994c).

(Manuscript received February 8, 1994; revision accepted for publication September 16, 1994.) 